\title{
Analysis of exploratory eye movements in patients with schizophrenia during visual scanning of projective tests' figures
}

Análise dos movimentos oculares de pacientes com esquizofrenia durante a exploração visual de figuras de testes projetivos

Katerina Lukasova', Lívia Lemos Zanin², Marcel Valois Chucre², Gamaliel Coutinho de Macedo³, Elizeu Coutinho de Macedo 2,4

\section{Keywords}

Schizophrenia, eye movements, Rorschach test, Thematic Apperception Test.

\section{Palavras-chave}

Esquizofrenia, movimento ocular, teste Rorschach, Teste de Apercepção Temática.

\begin{abstract}
Objective: Compare pattern of exploratory eye movements during visual scanning of the Rorschach and TAT test cards in people with schizophrenia and controls. Method: 10 participants with schizophrenia and 10 controls matched by age, schooling and intellectual level participated in the study. Severity of symptoms was evaluated with the Positive and Negative Syndrome Scale. Test cards were divided into three groups: TAT cards with scenes content, TAT cards with interaction content (TATfaces), and Rorschach cards with abstract images. Eye movements were analyzed for: total number, duration and location of fixation; and length of saccadic movements. Results: Different pattern of eye movement was found, with schizophrenia participants showing lower number of fixations but longer fixation duration in Rorschach cards and TAT-faces. The biggest difference was observed in Rorschach, followed by TAT-faces and TAT-scene cards. Conclusions: Results suggest alteration in visual exploration mechanisms possibly related to integration of abstract visual information.
\end{abstract}

\section{RESUMO}

Objetivo: Comparar o padrão do movimento ocular durante a inspeção dos cartões dos testes projetivos Rorschach e TAT em pessoas com esquizofrenia e controles. Método: Participaram 10 sujeitos com esquizofrenia e 10 controles, pareados por idade, escolaridade e nível de inteligência. A severidade dos sintomas foi avaliada com a Escala das Síndromes Positiva e Negativa. Os cartões dos testes foram divididos em três grupos: figuras do TAT representando ambientes, figuras do TAT com faces humanas e figuras abstratas do teste Rorschach. Os movimentos oculares foram analisados para: número total, duração e localização das fixações e comprimento dos movimentos sacádicos. Resultados: Foram encontradas diferenças no padrão do movimento ocular, e pessoas com esquizofrenia apresentaram menos fixações nos cartões do teste Rorschach e TAT-faces. Maiores diferenças foram observadas nos cartões do Rorschach, seguidos pelo TAT-faces e, por último, TAT-ambiente. Conclusões: Os resultados sugerem alteração nos mecanismos de exploração visual, possivelmente relacionada com a integração da informação visual abstrata.

1 Universidade Cruzeiro do Sul (Unicsul), Faculdade de Medicina da Universidade de São Paulo, Hospital das Clínicas (HCFMUSP), Neuroimagem Funcional (NIF), LIM44, Radiologia.

2 Universidade Presbiteriana Mackenzie (UPM), Faculdade de Psicologia, Centro de Ciências Biológicas e da Saúde.

3 HCFMUSP.

4 UPM, Centro de Ciências Biológicas e da Saúde.

Endereço para correspondência: Katerina Lukasova

Universidade Presbiteriana Mackenzie, Programa de Pós-Graduação em Distúrbios do Desenvolvimento

Rua da Consolação, 896 - 01302-907 - São Paulo, SP

Telefax: (11) 2114-8001

E-mail:katerinaluka@gmail.com 


\section{INTRODUCTION}

People with schizophrenia suffer from cognitive impairment related to memory, attention, and cognitive functioning with impact on different activities ${ }^{2}$. Studies aim to identify physiological and cognitive dysfunction which are present before and during the onset of the disease to enable a creation of new instruments and procedures for differential diagnosis $5^{3-5}$. The analysis of the eye movement pattern is one of the researched procedures that showed a possibility to distinguish, with $89.0 \%$ sensitivity, patients with schizophrenia from those with other psychiatric diseases and from healthy subjects ${ }^{6}$.

The basic properties of eye movements studied in schizophrenia are fixations and saccadic movements. Fixation occurs when the eyes stop for a brief time period (200-300 ms) enabling the visualized image to be focused and processed in different encephalic regions ${ }^{7}$. Rapid eye movements between two fixations are known as saccadic and their length depends on the characteristics of the stimulus observed, among other factors.

Two research approaches in eye movements of patients with schizophrenia have been explored. The first one verifies the pattern of fixations regarding figures with different contents and the second one analyzes the dynamic properties of the saccadic movements in the smooth pursuit tasks ${ }^{8}$. The following parameters are analyzed in both approaches to describe the pattern of visual scanning: total number of fixations the subject accomplishes during the visual scanning of a stimulus, mean duration of fixations and length of saccadic movements ${ }^{6}$. Differences between patients with schizophrenia and controls have been identified in different tasks: smooth pursuit eye movements ${ }^{3}$, closed-eye movements ${ }^{9}$, and exploratory eye movements ${ }^{10-12}$.

Different stimuli are used to analyze the pattern of visual scanning among subjects with schizophrenia. Comparing patients with schizophrenia and healthy subjects, variation of exploratory eye movements pattern is less pronounced when viewing stimuli, such as a landscapes ${ }^{13}$ and is greater during the visual exploration of human faces or a social context ${ }^{14}$. Images of real and concrete objects tend to be more easily perceived than non-structured, ambiguous and abstract images. Thus, abstract Rorschach test cards ${ }^{15}$ elicit higher level association and projection than when perceiving a scene and people in the Thematic Apperception Test $\left(\right.$ TAT) ${ }^{16}$ cards.

Rorschach test cards have been used to correlate eye movements with clinical symptoms and stimuli characteristics among schizophrenia patients ${ }^{11}$. Eye movements were registered during the 15 seconds that the cards were presented and the clinical symptoms were assessed by the Brief Psychiatric Rating Scale. The results indicated that the total number of fixations and the number of fixations in the areas of interest were lower albeit their duration was longer among patients with schizophrenia. Besides, the number of fixations in the areas was inversely correlated with positive symptoms. Thus, the visual exploratory eye movement behavior in patients with schizophrenia was affected by the characteristics of the visual stimuli and was correlated to clinical symptoms.

Other studies that used the Rorschach test cards ${ }^{17}$ aimed to verify whether abnormalities in visual tracking in schizophrenia are associated with deficits in the executive function. Indeed, results have shown that schizophrenia patients display a decrease in the number of fixations and an increase in the duration of fixation, which suggest impairment in the abilities of visual organization and processing of complex information. These findings indicate the possibility of using the measure of visual tracking in the search of a marker that identifies cognitive deficits in schizophrenia patients.

Other studies of exploratory eye movements use more concrete images, such as human faces with emotional and neutral expressions ${ }^{18}$. Results have shown that both patients with schizophrenia and healthy controls display more fixations in the faces with positive or negative emotional content than in neutral faces. However, subjects with schizophrenia showed fewer fixations, as well as fixations with longer duration. Besides, these eye movement parameters were related to the patients' clinical condition and intellectual level, since the duration of fixation was inversely correlated to the scores in the Raven Intelligence Test and the Positive and Negative Syndrome Scale (PANSS). These findings indicated the relevance of studies on eye movements, as for many psychological assessment tools used for assessment of people with schizophrenia require a good perception capacity'.

This study aimed to compare the pattern of exploratory eye movements during the visual scanning of the Rorschach and TAT projective tests between patients with schizophrenia and healthy controls. In Brazil, projective tests are still in great use for assessment in psychopathologies, specifically for screening of psychodynamic aspects of personality ${ }^{19}$. Besides, little validity and liability report, the performance on projective tests is influence by visual organization and processing of complex information. There for, the study intends to assess visual uptake strategies on different projective stimuli.

\section{METHODS}

\section{Participants}

Ten participants ( 7 men) with schizophrenia and 10 healthy controls matched at the individual level by gender, age, schooling, and intellectual level have participated. The mean age of participants was 29.3 years and they had 7.6 years of schooling. Participants with schizophrenia were diagnosed 
according to the DSM-IV-R and all were outpatients under drug treatment with the atypical antipsychotic risperidone for 1 to 2 years time. The average age of schizophrenia onset was 22.7 years $(S D=3.0)$ and had the mean record of 1.3 hospitalization ( $S D=1.2$ ). The exclusion criteria for both groups were: mental retardation, history of trauma or disease associated with sequels in the cognitive functions, history of schizoaffective disorder, substance abuse or disorders developed in childhood. None of the controls had a psychiatric history in their family members up to the third degree. All participants were with normal or corrected-to-normal vision. The participants had signed a written informed consent before the assessments, and the study was approved by the Institutional Ethical Review Board (no 914/04/2006).

\section{Instruments}

The Positive and Negative Syndrome Scale (PANSS) was used for the assessment of the severity of the positive and negative symptoms of the subjects with schizophrenia. PANSS is a widely used scale that provides balanced representation of symptoms and has been validated for Brazilian use ${ }^{20}$. The scale is composed by 30 items divided into 3 groups: positive, negative and general symptoms scales. The symptomatological type is determined according to the scores in each of the scales, being each item scored from 1 (absent) up to 7 (extremely severe). If three or more symptoms in the positive scale and less than three symptoms in the negative scale receive a score equal to or higher than 4 , then the symptomtology is Positive. If three or more symptoms in the negative scale and less than three symptoms in the positive scale receive a score equal to or higher than 4 , then the symptomatology is Negative. If three or more symptoms receive a score higher than or equal to 4 in both scales, the symptomatology is Mixed. When the former criteria are not met, the classification is None.

The general intelligence quotient $(\mathrm{IQ})$ was assessed with the Raven's Progressive Matrices Test. The test consists of 60 patterns from each of which a section has been removed and the correct answer is a best match selected from an array of six options displayed bellow each matrice. The use of Raven's Test was motivated by its less time consuming application and the fact that it is a culture-free test suitable for the use with São Paulo's low class population which due to migration has been exposed to different cultural influences.

The cards of the Rorschach and TAT projective tests were digitalized and displayed on the computer's screen. In this study, the cards I, II, V, VIII of the Rorschach test ${ }^{11}$ were used in addition to 8 cards of the TAT, that were divided in two groups according to the content of each card. Cards 2, 8, 9, and 13 depict scenes with images from nature, people, and other concrete objects. Cards 6, 7, 10, and 12 show faces of two persons involved in some type of interaction and relationship not easily interpretable. Therefore, three stimuli groups were formed: 4 TAT cards with scenes contents (TATscenes), 4 TAT cards with interaction content (TAT-faces), and 4 Rorschach cards with abstract images (ROR).

For presentation of the stimuli and eye movements tracking, the Eyegaze System ${ }^{\circledR}$ (LC Technologies Inc) was used. The system records eye movements in real time from the reflection of the cornea in the pupil's center (PCCR-Pupil-Center-Corneal Reflection) at a sampling frequency of 60 Hertz. We used a PC with an Intel Pentium ${ }^{\circledR}$ III processor with 128 Mb RAM memory, 2Mb screen board, 15" liquid crystal display with $800 \times 600$ pixels, camera support with high-speed infrared-sensitive lens and infrared light emitting diode. The average luminance of the screen with the stimulus frames presented was $85 \mathrm{~cd} / \mathrm{m}^{2}$ and that of the assessment room was $4 \mathrm{~cd} / \mathrm{m}^{2}$. We used an ophthalmologic device to support the subject's head (LF-M4, DFV S/A) as to prevent head movements and to keep the participants' eyes at 50 centimeters from the computer's screen ${ }^{21}$.

\section{Procedures}

At first, we selected the medical charts of patients who attended the mental health outpatient unit of a city in the Greater São Paulo and who met the inclusion criteria. In the first session we applied the PANSS scale and the Raven intelligence test ${ }^{22}$. In the second session, the eye movements were assessed during the visual scanning of the cards which were displayed on the screen for 10 seconds. At the end of the presentation of each card the participants should report what they had seen. Eye movement parameters registered were: Total Number of Fixations (NF), Mean Duration of Fixations (MDF), Mean Length of Saccadic Movements (MLS) and site of the fixations. The participants of the control group were selected among the outsourced employees of the University.

\section{RESULTS}

\section{Characterization of the participants}

There was no significant difference $\left(F_{[1,18]}=0.230, p<0.64\right)$ between the groups in the Raven test scores, although controls ( $M=29.40, S D=10.07)$ scored in average 3 points more than patients with schizophrenia ( $M=26.50, S D=16.23)$. The results on the PANSS scale indicated that 6 subjects scored for none, 2 for negative, 1 for positive and 1 for mixed symptomatological type. The mean dose of risperidone used was $4 \mathrm{mg} /$ day $(\mathrm{SD}=1.14)$.

\section{Analysis of eye movements}

The visual scanning pattern of the three groups of cards was analyzed by means of MANOVA for NF, MDF e MLS. Besides, the area in which fixations in the Rorschach test cards occurred was also described. The significance level adopted 
was $5 \%$. Levene's Test of Equality of Error Variances was performed to measure if the sample had equal variances. The mean values and the standard deviation for NF, MDF, and MLS are described in table 1.

Table 1. Visual scanning measures for the three groups of cards. Means and standard deviation (SD) are reported for Number of Fixations (NF), Mean Duration of Fixation in milliseconds (MDF) and Mean Length of Saccadic movements in degree of visual angle (MLS) in participants with schizophrenia and healthy controls

\begin{tabular}{lllll}
\hline & $\begin{array}{l}\text { Participants } \\
\text { with } \\
\text { schizophrenia } \\
(\mathrm{N}=10)\end{array}$ & $\begin{array}{l}\text { Healthy } \\
\text { controls } \\
(\mathrm{N}=10)\end{array}$ & Total & $\begin{array}{l}\text { MANOVAs } \\
\mathrm{F}_{[1,18]}\end{array}$ \\
\hline NF & $20.32(4.24)$ & $23.45(2.26)$ & $21.89(3.67)$ & $\mathrm{F}=4.23$ \\
(ROR) & & & & $p=0.05$ \\
NF & $24.33(4.20)$ & $28.15(3.36)$ & $26.24(3.86)$ & $\mathrm{F}=6.29$ \\
(TAT-faces) & & & & $p=0.02$ \\
NF & $25.95(4.09)$ & $29.08(3.06)$ & $27.51(3.86)$ & $\mathrm{F}=3.74$ \\
(TAT-scenes) & & & & $p=0.07$ \\
MDF (ms) & 478.09 & $413.62(46.3)$ & $445.86(96.16)$ & $\mathrm{F}=2.42$ \\
(ROR) & $(122.75)$ & & & $p=0.12$ \\
MDF & $385.98(15.30)$ & $330.24(34.48)$ & $358.11(77.92)$ & $\mathrm{F}=2.80$ \\
(TAT-faces) & & & & $p=0.11$ \\
MDF & $352.66(72.52)$ & $322.36(35.49)$ & $337.36(57.75)$ & $\mathrm{F}=1.44$ \\
(TAT-scenes) & & & & $p=0.25$ \\
MLS (deg) & $3.16(0.63)$ & $3.50(0.34)$ & $3.33(0.52)$ & $\mathrm{F}=2.28$ \\
(ROR) & & & & $p=0.15$ \\
MLS & $4.52(0.92)$ & $4.84(0.39)$ & $4.68(0.70)$ & $\mathrm{F}=1.16$ \\
(TAT-faces) & & & & $p=0.30$ \\
MLS & $5.22(0.93)$ & $5.26(0.55)$ & $5.25(0.72)$ & $\mathrm{F}=0.01$ \\
(TAT-scenes) & & & & $p=0.90$ \\
\hline & & & &
\end{tabular}

The NF in the three groups of cards was significantly different $\left(F_{[236]}=37.244, p<0.0001\right)$. Post-hoc analysis indicated that the number of fixations in the ROR $(M=21.89$, $\mathrm{SD}=3.67)$ was significantly lower $(\mathrm{p}<0.001)$ compared to the TAT-faces $(M=26.24, S D=3.86)$ and the TAT-scenes $(M$ $=27.51, \mathrm{SD}=3.86)$. No significant difference was found in NF between both types of TAT cards $(p<0.09)$. In the group analyses, there was a significant main effect $\left(F_{[1,18]}=6.294\right.$, $p=0.02$ ). Indeed, an analysis with MANOVAs showed that participants with schizophrenia made significantly less fixations than controls for TAT-faces and ROR (both $p<0.05$ ), but not for TAT-scenes $(p<0.1)$. Levene's Test of Equality of Error Variances revealed that the variances were equal across groups.

As for the MDF, within a limited stimulus presentation time of 10 seconds, the MDF and NF are proportionally related and the higher number of fixations reflects on the shorter fixation's durations. Although, the MDF - NF relation is not linear since some time is spend on saccades and drifts, a high similarity between the NF and MDF analyses is expected. For MDF, MANOVA indicated a significant differ- ence between groups of cards $\left(F_{[2,36]}=26.338, p<0.0001\right)$. Post-Hoc LSD Analysis revealed that ROR had a significantly higher MDF ( $M=445.86, S D=96.16, p<0.001)$ when compared to the TAT-faces $(M=358.11, S D=77.92)$ and the TATscenes $(M=337.36, S D=57.75)$. There was no significant difference between the two types of TAT cards. In the group analyses, there was not a significant main effect $\left(F_{[1,18]}=3.064\right.$, $\mathrm{p}<0.1$.

The MLS was also significantly different between the groups of cards $\left(F_{[2,36]}=177.851, p<0.0001\right)$. Post-Hoc LSD Analysis indicated that in the TAT-scenes cards, the mean length of saccades was significantly higher $\left(M=5.25^{\circ}\right.$, SD $\left.=0.72^{\circ}\right)$ than those in the TAT-faces cards $\left(\mathrm{M}=4.68^{\circ}, \mathrm{SD}=\right.$ $\left.0.70^{\circ}, p<0.0001\right)$ and the ROR $\left(M=3.33^{\circ}, S D=0.52^{\circ}, p<\right.$ $0.0001)$. MLS was not significantly different between groups $\left(F_{[1,18]}=0.80, p=0.383\right)$ although schizophrenia participants had in average a lower mean saccade length between two fixation points.
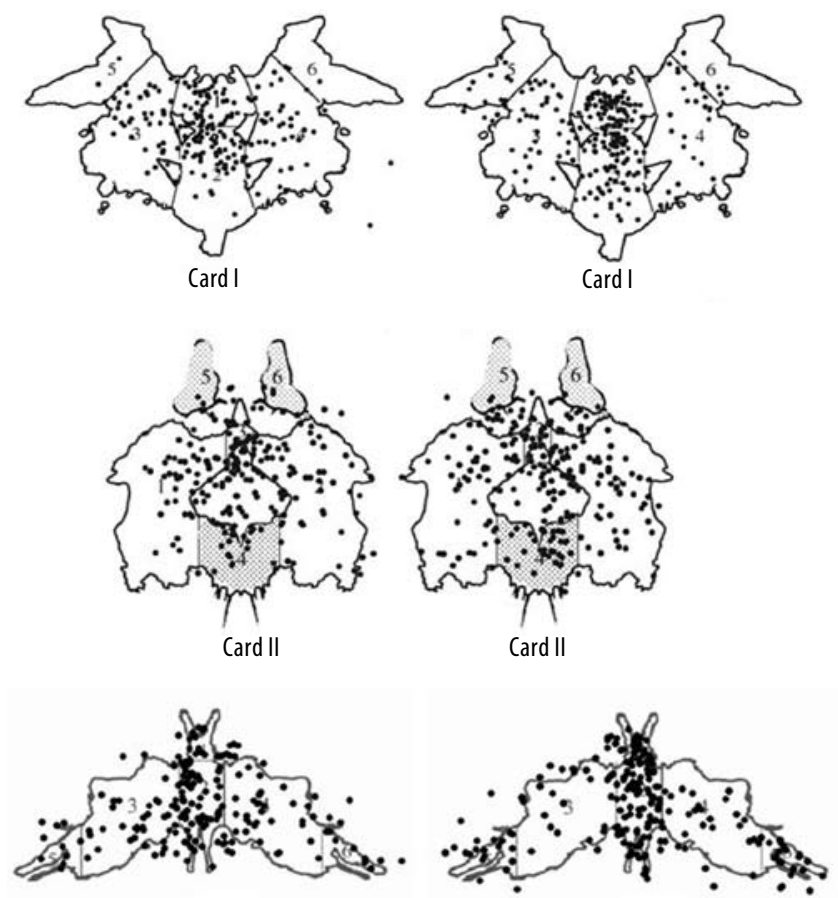

Card V

Card V

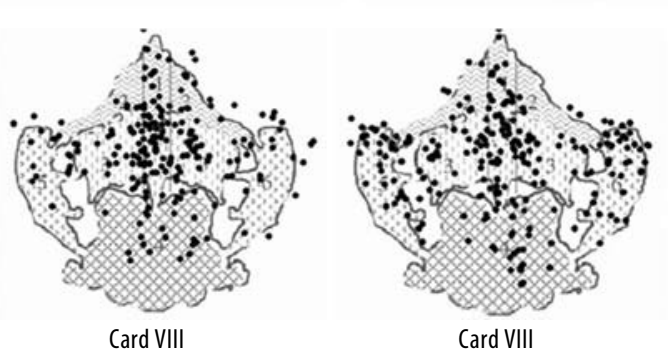

Figure 1. Example of scanning behavior on Rorschach cards showing the distribution of fixations of all participants with schizophrenia (the left figure of each pair) and healthy controls (right figure of each pair). 
Figure 1 shows the fixations of both groups of participants in the Rorschach cards. Considering that both groups differed regarding the number of fixations in the Rorschach cards, a new analysis was done to verify if they also differed regarding the area of the fixations. For quantitative assessment of fixations' distribution, three areas of interest (AOI) were defined in three regions: central $(C)$, left $(L)$ and right $(R)$. These regions were defined according to the areas outlined in the Classification Manual of the Rorschach Comprehensive System ${ }^{15}$. Thus, the AOls comprised different areas. In card I, region $C$ corresponded to areas 1 and 2; region $E$, to areas 3 and 5 , and region $D$, to areas 4 and 6 . In card $I I$, region $C$ corresponded to areas 3 and 4; region E, to areas 1 and 5; and region $D$, to areas 2 and 6 . In card $V$, region $C$ corresponded to areas 1 and 2; region $E$, to areas 3 and 5 , and region $D$, to areas 4 and 6 . Finally, in card VIII, region C corresponded to areas 1, 2, 3 and 4; region $E$, to area 5 and region $D$, to area 6 . The fixation rate for each $\mathrm{AOI}$ was calculated by dividing the absolute fixation number in $\mathrm{AOI}$ area by the card's total number of fixations and multiplied by 100 .

Between-groups MANOVAs were accomplished, but there was no significant difference in the proportion of fixation for AOls of any card $\left(F_{[1,18]}=2.63, p<0.2\right)$. Within-subjects analysis showed a main effect for AOls $\left(F_{[2,36]}=73.46, p<\right.$ 0.001 ), with both groups showing more fixations in the central AOls, than in the peripheral ones (Table 2).

Table 2. The fixation rate and Standard Deviation (SD) for the three Areas of Interest (AOI) in the Rorschach test cards

\begin{tabular}{|c|c|c|c|c|c|c|c|}
\hline \multirow[b]{2}{*}{ AOls } & \multicolumn{3}{|c|}{$\begin{array}{l}\text { Participants with schizophrenia } \\
(\mathrm{N}=10)\end{array}$} & \multicolumn{3}{|c|}{$\begin{array}{l}\text { Healthy controls } \\
(\mathrm{N}=10)\end{array}$} & \multirow[t]{2}{*}{$\begin{array}{l}\text { MANOVAs } \\
\mathrm{F}_{[0,18]}\end{array}$} \\
\hline & Left & Central & Right & Left & Central & Right & \\
\hline $\begin{array}{l}\text { Card I } \\
\text { (\%) } \\
\text { (SD) }\end{array}$ & $\begin{array}{l}18.34 \\
(15.74)\end{array}$ & $\begin{array}{l}56.95 \\
(19.78)\end{array}$ & $\begin{array}{l}23.32 \\
(17.45)\end{array}$ & $\begin{array}{l}19.19 \\
(11.89)\end{array}$ & $\begin{array}{l}63.56 \\
(18.44)\end{array}$ & $\begin{array}{l}17.23 \\
(9.81)\end{array}$ & $\begin{array}{l}\mathrm{F}=1.8 \\
p=0.2\end{array}$ \\
\hline $\begin{array}{l}\text { Card II } \\
\text { (SD) }\end{array}$ & $\begin{array}{l}16.01 \\
(10.27)\end{array}$ & $\begin{array}{l}72.92 \\
(12.96)\end{array}$ & $\begin{array}{l}11.06 \\
(11.85)\end{array}$ & $\begin{array}{l}20.31 \\
(16.59)\end{array}$ & $\begin{array}{l}71.95 \\
(15.30)\end{array}$ & $\begin{array}{l}7.74 \\
(5.93)\end{array}$ & $\begin{array}{l}\mathrm{F}=0.4 \\
p=0.7\end{array}$ \\
\hline $\begin{array}{l}\text { Card V } \\
\text { (SD) }\end{array}$ & $\begin{array}{l}19.51 \\
(7.95)\end{array}$ & $\begin{array}{l}47.64 \\
(25.07)\end{array}$ & $\begin{array}{l}32.84 \\
(26.73)\end{array}$ & $\begin{array}{l}19.27 \\
(13.48)\end{array}$ & $\begin{array}{l}54.07 \\
(8.86)\end{array}$ & $\begin{array}{l}26.03 \\
(9.62)\end{array}$ & $\begin{array}{l}\mathrm{F}=0.3 \\
p=0.7\end{array}$ \\
\hline $\begin{array}{l}\text { Card } \\
\text { VIII } \\
\text { (SD) }\end{array}$ & $\begin{array}{l}15.88 \\
(6.41)\end{array}$ & $\begin{array}{l}69.56 \\
(20.27)\end{array}$ & $\begin{array}{l}13.80 \\
(14.71)\end{array}$ & $\begin{array}{l}25.56 \\
(13.98)\end{array}$ & $\begin{array}{l}54.17 \\
(23.61)\end{array}$ & $\begin{array}{l}20.24 \\
(11.48)\end{array}$ & $\begin{array}{l}\mathrm{F}=2.1 \\
p=0.1\end{array}$ \\
\hline
\end{tabular}

\section{DISCUSSION}

This study aimed to describe and compare the exploratory eye movement pattern displayed in the scanning of cards of the Rorschach and TAT projective tests in patients with schizophrenia and controls. There were differences in the pattern of eye movements according to the type of stimulus with schizophrenia patients making fewer fixations when compared to controls. The difference in these properties of exploratory eye movement was higher in the Rorschach test cards, followed by the TAT-faces and TAT-scenes. Changes in visual scan pattern was found in other studies indicating that eye movement properties are altered in schizophrenia patients ${ }^{6,11-13,23,24}$ and in their first-degree relatives ${ }^{4}$.

Eye movement studies show that even in simple tasks, such as saccades directed to a target, the generation of eye movements is mediated by bottom-up sensorial processes and top-down complex cognitive processes. During the visual perception, there is an intermediation between the encephalic stem structures, such as the superior colliculos, which are involved in the mapping of the visual space and are connected to cortical structures, such as the frontal cortex, which is involved in the planning of the direction and inhibition of the saccades ${ }^{25}$. Therefore, even in the simple visual scanning tasks, the pattern of eye movement is influenced and can be also modified by the type and complexity of the stimulus and the instruction received ${ }^{26}$. Indeed, eye movement patterns differ between subjects with schizophrenia and attention-deficit hyperactivity disorder (ADHD) depending on the type of instruction given and the requested response. Subjects with schizophrenia showed longer fixations and shorter lengths of saccadic movements when they watched simple drawings and answered to global questions about what was happening. However, focal questions about a specific fact of the figure did not generate different pattern from those found in healthy controls and participants with $\mathrm{ADHD}^{27}$.

In this study, the instruction given was the same for all the cards, independently of their content. Thus, the differences found in exploratory eye movement pattern changed according to the cognitive demand that each stimulus represented for the observer's perceptual processing. In ROR cards, a concrete object is perceived from abstract inkblots. As for the TAT-faces and TAT-scenes, the presence of two human faces suggesting interaction and landscape requires a global processing. The results of this study showed that all the participants responded to the change in stimulus by the change in number of fixation. Since there is expected an inverted relation between number of fixations and fixation duration in limited exposition time, one could suggests that highly structured stimulus such as TAT-scenes evoke more dynamic externally driven eye scan, while less structured abstract inkblots and TAT faces stimulate less fixations of longer duration, possibly a reflection of internally driven stimulus integration. It was on these kind of stimulus that participants with schizophrenia differed from healthy controls and presented reduced visual exploration.

For the saccades length, the difference between the groups on Rorschach inkblots was bigger, though not significantly, than on TAT-scenes and the lack of significance can be due to the small size of sample. Other studies found significance differences in saccades length on Benton Test ${ }^{12}$ and schematic drawings of human faces ${ }^{13,28}$. 
Visual-processing deficit, a well documented difficulty to perceive figure-ground pictures and objects partially obstructed or fragmented, was found in individuals at clinical high risk for psychoses, which did not differ from in-patients with schizophrenia on Rorschach inkblots perception ${ }^{29}$. Reduced visual exploration can be responsible for visual-processing deficit. As our results indicate, such a deficit is more top-down related considering a similar intake strategy showed by fixations proportion on Rorschach cards areas of interest. Schizophrenia participants placed their fixations proportionally in similar areas as their healthy controls. Thus, an uptake of visual information was accomplished but its integration might be slowed on high level bases. To what extent this is due to medication remains unclear. Studies correlating eye movement properties, symptomatology and medication dose have shown dis-

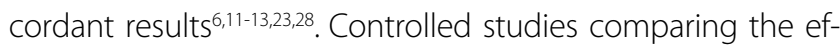
fects of risperidone and olanzapine have found a decrease in the mean length of the saccadic movements in schizophrenia patients compared to controls but no difference was found among patients due to the medication type ${ }^{30}$.

To explain a cause of a reduced visual exploration is beyond the scope of this study and further studies are needed to investigate the role of executive function in visual information integration and the effect of medication on eye movements. One of the draw backs of the present study was the limited number of participants with schizophrenia. This should be taken in consideration for the findings' generalization. Other limitation is a lack of interrogation after the cards application so that correlation could be made between an eye movements and the person's perception. The last point to be addressed is a need to include experimental groups with different medication, so that a possible influence of drugs on the eye movements is assessed.

\section{CONCLUSION}

This study described eye movement properties during the scanning of projective tests' cards and found different pattern of eye movements in participants with schizophrenia in abstract stimulus that can be attributed to altered integration of visual information. It pointed to the relevance of studies on eye movements, since projective tests are instruments frequently used in the psychological assessment. Other studies with larger groups of participants should replicate the procedure and further investigate the attention mechanisms involved in abstract stimulus processing.

\section{ACKNOWLEDGMENTS}

All authors of the manuscript declare that there were no conflicts of interest that could have influenced the results of the research. ECM is researcher 1D of National Council for Scien- tific and Technological Development (CNPq) and is supported by a CNPq grant (305356/2005-4) and by MackPesquisa.

\section{REFERENCES}

1. Berberian A, Trevisan B, Moriyama T, Montiel J, Oliviera J, Seabra A. Working memory assessment in schizophrenia and its correlation with executive functions ability. Rev Bras Psiquiatr [online]. 2009;31(3):219-26.

2. Louzã M, Monteiro L. Alterações cognitivas na esquizofrenia: consequências funcionais e abordagens terapêuticas. Psiq Clin. 2007;34(2):179-83.

3. Holzman PS, Proctor L, Huges D. Eye tracking patterns in schizophrenia. Science. 1973;181(4095):179-81

4. Calkins ME, lacono WG, Denis SO. Eye movement dysfunction in first-degree relatives of patients with schizophrenia: a meta-analytic evaluation of candidate endophenotypes. Brain Cogn. 2008;68(3):436-61.

5. Ettinger U, Kumari V, Crawford TJ, Corr PJ, Das M, Zachariah E, et al. Smooth pursuit and antisaccade eye movements in siblings discordant foe schizophrenia. J Psychiatr Res. 2004;38(2):177-84.

6. Kojima T, Matsushima E, Cota K, Toru M, Han Y, Shen Y, et al. Stability of exploratory eye movements as a marker of schizophrenia - a WHO multi-center study. Schizophr Res. 2001;52(3):203-13.

7. Rayner K. Eye movements in reading and information processing: 20 years of research. Psychol Bull. 1998;124(3):372-422.

8. Lencer R, Trillenberg-Krecker K, Schwinger E, Arolt V. Schizophrenia spectrum disorders and eye tracking dysfunction in singleton and multiplex schizophrenia families. Schizophr Res. 2003;60(1):33-45.

9. Nakamura M, Matsushima E, Ohta K, Ando K, Kojima T. Relationship between attention and arousal level in schizophrenia. Psychiatry Clin Neurosci. 2003;57(5):472-7.

10. Matsushima E, Kojima T, Ohta K. Exploratory eye movement dysfunctions in patients with schizophrenia: possibility as a discriminator for schizophrenia. J Psychiatr Res. 1998;32(5):289-95

11. Hori Y, Fukuzako H, Sugimoto $Y$, Takigawa M. Eye movement during the Rorschach Test in Schizophrenia. Psychiatry Clin Neurosci. 2002;56(4):409-18.

12. Obayashi S, Matsushima E, Ando H, Kojima T. Exploratory eye movements during the Benton Visual Retention Test: characteristics of visual behavior in schizophrenia. Psychiatry Clin Neurosci. 2003;57(4):409-15.

13. Ryu H, Morita Y, Shoji Y, Maeda H. Abnormal exploratory eye movements in schizophrenic patients vs healthy subjects. Acta Neurol Scand. 2001;(104):369-76.

14. Green M, Waldron J, Simpson I, Coltheart M. Visual processing of social context during mental state perception in schizophrenia. J Psychiatry Neurosci. 2008;33(1): 34-42.

15. Exner JE. Manual de Classificação do Rorschach para o Sistema Compreensivo. Tradução: Antonio Carlos Pacheco. São Paulo: Casa do Psicólogo; 1999.

16. Silvia MVM. TAT: aplicação e interpretação do teste de apercepção temática. São Paulo: EPU; 1989.

17. Minassian A, Granholm E, Verney S, Perry W. Visual Scanning deficits in schizophrenia and their relationship to executive functioning impairment. Schizophr Res. 2004;74(1):69-79.

18. Lukasova K, Macedo E, Valois M, Macedo G, Schwartzman J. Percepção de expressões faciais em pessoas com esquizofrenia: movimentos oculares, sintomatologia e nível intelectual. Psico-USF. 2007;12(1):95-102.

19. Johann RVO, Vaz CE. Avaliação de aspectos cognitivos em homens portadores de esquizofrenia em tratamento com haloperidol ou clozapina. J Bras Psiquiatr. 2006;55(3):202-7.

20. Vessoni ALN. Adaptação e Estudo da Confiabilidade da Escala de Avaliação das Síndromes Positiva e Negativa para a Esquizofrenia no Brasil [dissertation]. Escola Paulista de Medicina: São Paulo; 1993.

21. Macedo EC, Covre P, Orsati FT, Okada M, Schwartzman JS. Análise dos padrões dos movimentos oculares em tarefas de busca visual: efeito da familiaridade e das características físicas do estímulo. Arq Bras Oftalmol. 2007;70:31-6.

22. Raven JC, Campos F. Matrizes progressivas. Rio de Janeiro: (EPA; 2003. 
23. Wolwer W, Wolfgang, G. Impaired Trail-Making Test-B performance in patients with acute schizophrenia is related to inefficient sequencing of planning and acting. J Psychiatr Res. 2002:36(6):407-16.

24. Macedo, EC, Lukasova, K, Macedo, GC, Duduchi M, Capovilla FC, Schwartzman JS. Avaliaçãa neuropsicológica e análise dos movimentos oculares na esquizofrenia. In: Macedo EC, Capovilla FC (Org.). Temas em neuropsicolinguística. Ribeirão Preto: Tecmedd; 2005, p.12-27.

25. McDowell JE, Dyckman KA, Austin BP, Clementz BA. Neurophysiology and neuroanatomy of reflexive and volition saccade: evidence from studies of humans. Brain Cogn. 2008;68(3):255-70

26. E Isotalo, Lasker AG, Zee DS. Cognitive influences on predictive saccadic tracking. 2005;165(4):461-9.
27. Karetekin C, Asarnow RF. Exploratory eye movements to pictures in childhood-onset schizophrenia and attention-deficit/hyperactivity disorder (ADHD). J Abnorm Child Psychol. 1999;27(1):35-49.

28. Nakayama H, Morita K, Mori K, Hirai S, Maeda H. Improvement of exploratory eye movements in schizophrenic patients during recovery period. Psychiatry Clin Neurosci. 2003;57(2):169-76

29. Kimhy D, Corcoran C, Harkavy-Friedman JM, Ritzler B, Javitt DC, Malaspina D. Visual form perception: a comparison of individuals at high risk for psychosis, recent onset schizophrenia and chronic schizophrenia. Schizophr Res. 2007;97(1-3):25-34.

30. Reilly JL, Lencer R, Bishop JR, Keedy S, Sweeney JA. Pharmacological treatment effects on eye movement control. Brain Cogn. 2008;68(3):415-35. 